\title{
Assessment of Anthropometric Indices for Optimal Cut-Offs for Obesity Screening in a South African Adolescent Population
}

\author{
Godwill Azeh Engwa 1,+(D), Karin Schmid-Zalaudek $2,+\left(\mathbb{D}\right.$, Chungag Anye $^{3} \mathbb{D}$, Boitumelo P. Letswalo ${ }^{4}$, \\ Paul Chungag Anye ${ }^{5}$, Muhau Muhulo Mungamba ${ }^{4}$ (D), Constance Rufaro Sewani-Rusike ${ }^{4}$, Nandu Goswami ${ }^{2, *}$ (D) \\ and Benedicta Ngwenchi Nkeh-Chungag ${ }^{1, * \mathbb{D}}$
}

1 Department of Biological and Environmental Sciences, Faculty of Natural Sciences, Walter Sisulu University, Mthatha 5117, South Africa; gengwa@wsu.ac.za

2 Physiology Division, Otto Loewi Research Center for Vascular Biology, Immunology and Inflammation, Medical University of Graz, Neue Stiftingtalstrasse 6, D-5 A 8036 Graz, Austria; karin.schmid@medunigraz.at

3 Dayenuel Consulting, Postnet Suites 092, Mthatha 5099, South Africa; foyarrh52@gmail.com

4 Department of Human Biology, Faculty of Natural Sciences, Walter Sisulu University, Mthatha 5177, South Africa; bletswalo@wsu.ac.za (B.P.L.); mmungamba@wsu.ac.za (M.M.M.); crusike@wsu.ac.za (C.R.S.-R.)

5 MBCHB Programme, Faculty of Health Sciences, Walter Sisulu University PBX1, Mthatha 5117, South Africa; 214023362@wsu.ac.za

* Correspondence: nandu.goswami@medunigraz.at (N.G.); bnkehchungag@wsu.ac.za (B.N.N.-C.)

+ Contributed equally to the manuscript as first authors.

Citation: Engwa, G.A.;

Schmid-Zalaudek, K.; Anye, C.; Letswalo, B.P.; Anye, P.C.;

Mungamba, M.M.;

Sewani-Rusike, C.R.; Goswami, N.;

Nkeh-Chungag, B.N. Assessment of Anthropometric Indices for Optimal Cut-Offs for Obesity Screening in a South African Adolescent Population. Biology 2021, 10, 1118. https:// doi.org/10.3390/biology10111118

Academic Editor: Paulo Gentil

Received: 17 August 2021

Accepted: 15 October 2021

Published: 29 October 2021

Publisher's Note: MDPI stays neutral with regard to jurisdictional claims in published maps and institutional affiliations.

Copyright: (c) 2021 by the authors. Licensee MDPI, Basel, Switzerland. This article is an open access article distributed under the terms and conditions of the Creative Commons Attribution (CC BY) license (https:// creativecommons.org/licenses/by/ $4.0 /)$.
Simple Summary: The diagnosis of obesity in sub-Saharan African children relies on cut-off values for body mass index percentile (pBMI) and waist-to-height ratio (WtHR) established in western populations. Hence, this study assessed anthropometric indices to determine optimal cut-off values for obesity screening in the South African adolescent population. Findings from this study showed that the cut-off value for $\mathrm{pBMI}$ was p85.2th, which improved the sensitivity of the test by approximately $30 \%$ compared to the CDC recommended BMI percentile of p95.0th. Moreover, the optimal cut-off for WHtR was 0.481 , which was close to the recommended cut-off value of 0.5 . This study reveals a lower pBMI cut-off value, different from the CDC recommended cut-off, for screening obesity in a South African adolescent population and suggests that the optimal pBMI cut-off for obesity screening may be ethnic-specific.

Abstract: The assessment of obesity in sub-Saharan Africa relies on cut-offs established from western populations. This study assessed anthropometric indices to determine optimal cut-off values for obesity screening in the South African adolescent population. A cross-sectional study involving 1144 (796 females and 348 males) adolescents aged 11-17 years from the Eastern Cape Province of South African was conducted. Anthropometric parameters were measured. Receiver operating characteristic (ROC) analysis was performed to assess the sensitivity and specificity of obesity screening tools and establish cut-offs. The optimal cut-offs for obesity in the cohort using waist-to-height ratio (WHtR) as reference were: neck circumference $(\mathrm{NC})=30.6 \mathrm{~cm}$, mid-upper arm circumference $($ MUAC) $=25.9 \mathrm{~cm}$, waist circumference $(W C)=75.1 \mathrm{~cm}$, hip circumference $(\mathrm{HC})=92.15 \mathrm{~cm}$ and body mass index percentile $(\mathrm{pBMI})=\mathrm{p} 85.2 \mathrm{th}$. The new $\mathrm{pBMI}$ cut-off value at $\mathrm{p} 85.2 \mathrm{th}$ improved the sensitivity of the test by approximately $30 \%$ compared to the CDC recommended BMI percentile (pBMIr) of p95.0th. When pBMI was used as reference, the optimal cut-offs in the cohort were: $\mathrm{WHtR}=0.481, \mathrm{NC}=30.95 \mathrm{~cm}, \mathrm{MUAC}=27.95 \mathrm{~cm}, \mathrm{WC}=76.1 \mathrm{~cm}$ and $\mathrm{HC}=95.75 \mathrm{~cm}$. The WHtR optimal cut-off of 0.481 was close to the recommended cut-off value of 0.5 . The predicted prevalence of obesity obtained using cut-offs from ROC analysis was higher than those from recommended references. All cut-off values for the various anthropometric measures generally increased with age for all percentile ranges. This study reveals a lower pBMI cut-off value, different from the CDC recommended cut-off, for screening obesity in a South African adolescent population. The study has established that the optimal pBMI cut-off for obesity screening may be ethnic-specific. 
Keywords: obesity; anthropometric measures; cut-off values; South Africans of African ancestry

\section{Introduction}

Childhood obesity is increasingly becoming a public health problem, as its prevalence is rapidly on the rise worldwide [1]. Recent reports estimate that over 40 million children below 5 years of age and over 330 million children and adolescents aged 5-19 years were overweight or obese in 2016 [2]. It has also been reported that children with obesity are more susceptible to metabolic and cardiovascular risk factors [3-6], such as dyslipidaemia [7], high blood pressure [5,8,9] and hyperglycaemia [10]. Several studies have indicated that these conditions may track into adulthood, leading to the development of chronic diseases linked with lifestyle changes such as diabetes, hypertension and cardiovascular diseases (CVDs) [11-13] associated with early morbidity and premature death [14].

Several anthropometric measurements, ratios and indices, including waist circumference (WC), waist-to-hip ratio (WHR) and body mass index (BMI), have been used to assess obesity and the risk of obesity-related diseases in children [15]. While WC and WHR have been considered as measures for abdominal or central obesity, BMI has been considered as a measure for general obesity. Waist-to-height ratio (WHtR) [16] and neck circumference (NC) [17], as well as mid-upper arm circumference (MUAC) [18], have also been suggested as being useful assessment tools for childhood obesity. Age- and sex-specific BMI percentile curves (pBMI) are the most frequently used measures for obesity screening in children of all ages, while WC and WHtR are specific for assessing abdominal fat in children [19,20]. A few studies claim that WHtR is not age or gender (sex) dependent and is therefore a better predictor for obesity-related cardiometabolic risk factors than WC or BMI in adults [21,22]. This corroborates the fact that central obesity poses a greater health risk than general obesity. However, in children, it remains unclear whether WHtR is better than WC or BMI in assessing obesity [23].

Researchers have tried to find simpler and easier strategies to distinguish between children with and without obesity. Based on research findings, the World Health Organization (WHO) [24], the United States Centers for Disease Control and Prevention (CDC) [25] and the International Obesity Task Force (IOTF) [26] have established cut-offs for obesity screening using pBMI. While the WHO pBMI cut-off relies on data from only healthy children, the IOTF cut-off is complex to extrapolate, as it links the cut-off for children to the BMI of 18-year-old adults at 25 and $30 \mathrm{~kg} / \mathrm{m}^{2}$. As such, the CDC cut-off is preferable for the children population because it has no restrictions on their health status. According to the CDC, pBMI higher than the 95th percentile ( $\geq$ p95) is indicative of obesity in children [25]. Ashwell et al. (2012), on the other hand, used the ratio of WC to height (WHtR) to determine a cut-off value of 0.5 , which is widely accepted for indicating obesity in both children and adults, irrespective of sex [27]. However, these cut-off points (pBMI and WHtR) were derived from Caucasian populations and are also recommended for assessing obesity and cardiometabolic risks in people of African ancestry, without consideration for African growth patterns [28]. Although the birth to 22 years cohort study in South Africa showed association between relative weight gain and abdominal adiposity outcomes concurring with findings from western populations, it did not show a relative linear growth relationship with adiposity in the adolescent age group [29]. There is evidence that ethnic diversity could be accountable for differences in measures of adiposity and cardiometabolic risk, as several studies have shown varying cut-offs for obesity in different populations [19,30].

The prevalence of obesity in South Africa is steadily on the rise [31], especially in the paediatric population [32]. Recent reports show an increase in the prevalence of obesity in South African children [33] and adolescents [34] of African ancestry, using cut-off points established from western populations. To date, no cut-off values have been established for obesity screening in the South African adolescent population. This study aims to assess 
anthropometric indices to determine optimal cut-off values for obesity screening in a South African adolescent population.

\section{Materials and Methods}

\subsection{Study Population and Design}

This was a cross-sectional study that included 1144 (348 males and 796 females) South African adolescents aged 11-17 years old recruited from Libode, Mthatha, East London and Alice of the Eastern Cape Province of South Africa from June 2016 to December 2017. The Eastern Cape Province is predominately dominated by South Africans of African ancestry.

\subsection{Ethical Consideration}

Ethical clearance was obtained from the Health Sciences Ethics Committee of Walter Sisulu University (Ref No: 112/2018) and University of Fort Hare (CH1011SCHU01), South Africa. After careful explanation of the aim and objectives of the study, written informed consent was obtained from the parents/legal guardians of the children before enrolment into the study. The study adhered to the standards of reporting and was in accordance with the South Africa National Data Protection Act and the identities of the participants were kept confidential.

\subsection{Anthropometric Measurements}

Anthropometric measurements were performed in accordance with the International Standards for Anthropometric Assessments [35] for all participants. Height was measured using a wall-mounted Harpenden stadiometer and recorded to the nearest $0.1 \mathrm{~cm}$. Weight was measured using a Tanita weight scale (BC1000, Tanita Corporation, Tokyo, Japan) and body mass index (BMI) determined as weight $/$ height ${ }^{2}\left(\mathrm{~kg} / \mathrm{m}^{2}\right)$. Obtained BMI was converted to BMI percentiles (pBMI) for age, sex and height as underweight: $<5$ th percentile, normal weight: $\geq 5$ th to $<85$ th percentile, overweight: $\geq 85$ th to $<95$ th percentile and obese: $\geq 95$ th percentile [36]. The waist circumference (WC), hip circumference (HC), mid-upper arm circumference (MUAC) and neck circumference (NC) were measured in centimetres $(\mathrm{cm})$ using an anthropometric tape. The waist-to-height ratio $(\mathrm{WHtR})$ was calculated from WC and height, and a cut-off value of 0.5 was used to classify obesity, as previously reported [21].

\subsection{Data and Statistical Analysis}

The prevalence (\%) of obesity was calculated as (presence of obesity/total population) $\times 100$. The specificity and sensitivity of obesity by pBMI, using WHtR as reference, were calculated from true-positive (TP), true-negative (TN), false-negative (FN) and falsepositive $(\mathrm{FP})$ results. Sensitivity was calculated as $\mathrm{TP} /(\mathrm{TP}+\mathrm{FN}) \times 100$ and specificity as $\mathrm{TN} /(\mathrm{TN}+\mathrm{FP}) \times 100$.

Data were analysed using Statistical Package for Social Sciences (SPSS) software (version 20, IBM SPSS Inc., 2011, Chicago, IL, USA). Mean differences between groups were analysed by t-test or ANOVA/ANCOVA, controlling for age and sex. Comparison of categorical variables between groups was performed using chi-square test of association. Receiver operating characteristic (ROC) curve analysis, as previously reported [37], was used as a screening tool to determine cut-off points for pBMI, WC, WHtR, HC, NC and MUAC to classify obesity. Sensitivity and specificity were determined from the ROC curve to evaluate the accuracy of the pBMI, WC, WHtR, HC, MUAC and NC classifications in the determination of obesity, using either pBMI or WHtR as reference. The ROC curve is a plot of the sensitivity (true-positive rate) against 1-specificity (false-positive rate) for each anthropometric measure. The area under the curve (AUC) is an indicator of how precise an anthropometric measure distinguishes a positive outcome. The AUC values range between 0 and 1 . A value of 1 indicates an ideal performance while 0.5 , indicated by a diagonal line, demonstrates that the anthropometric measure has no predictive performance. The Youden index (value of the largest sum of sensitivity and specificity -1) was used to determine 
the optimal cut-off value for each anthropometric index (BMI, WC, WHtR, HC, WC and MUAC). The data for all age groups were classified into percentiles for males and females, and percentile values identified. A difference was considered as significant at $p \leq 0.05$.

\section{Results}

The characteristics of the participants are summarised in Table 1. Since females were on average slightly older $\left(\mathrm{t}_{(1142)}=6.79, p<0.001\right)$, age was considered as a covariate in the comparison of anthropometric variables by ANCOVA. Females were on average taller $\left(\mathrm{F}_{(1,1141)}=9.11, p=0.003\right)$, but not heavier than males $\left(\mathrm{F}_{(1,1141)}=3.10, p=0.079\right)$. Females had higher BMI and pBMI $\left(\mathrm{F}_{(1,1141)}=13.96, p<0.001\right)$, WHtR $\left(\mathrm{F}_{(1,1141)}=6.61, p=0.010\right)$, $\operatorname{MUAC}\left(\mathrm{F}_{(1,1141)}=10.50, p=0.001\right)$ and $\operatorname{HCs}\left(\mathrm{F}_{(1,1141)}=14.42, p<0.001\right)$ when controlling for age. No significant differences were found in NC $\left(\mathrm{F}_{(1,1141)}=0.90, p=0.342\right)$ and WC $\left(\mathrm{F}_{(1,1141)}=2.46, p=0.117\right)$ between males and females.

Table 1. Baseline characteristics of the study population.

\begin{tabular}{lccccccc}
\hline & \multicolumn{3}{c}{ Females $(\boldsymbol{n = 7 9 6 )}$} & \multicolumn{3}{c}{ Males $(\boldsymbol{n = 3 4 8 )}$} \\
\cline { 2 - 7 } & Mean \pm SD & CI & Min.-Max. & Mean \pm SD & CI & Min.-Max. & $p$-Value \\
\hline Age (years) & $13.88 \pm 1.61$ & $13.77,14.00$ & $11-17$ & $13.17 \pm 1.70$ & $12.99,13.35$ & $11-17$ & 0.001 \\
Weight (kg) & $55.38 \pm 15.11$ & $54.32,56.43$ & $26.7-112.50$ & $50.97 \pm 15.32$ & $49.36,52.59$ & $24.0-108.69$ & 0.079 \\
Height (m) & $1.56 \pm 0.08$ & $1.56,1.57$ & $1.31-1.88$ & $1.56 \pm 0.11$ & $1.55,1.57$ & $1.28-1.86$ & 0.003 \\
BMI (m/h $\left.\mathbf{h}^{2}\right)$ & $22.43 \pm 5.30$ & $22.06,22.80$ & $13.55-42.00$ & $20.57 \pm 4.73$ & $20.07,21.07$ & $13.50-41.50$ & 0.001 \\
pBMI & $64.83 \pm 28.87$ & $62.81,66.85$ & $0.6-99.8$ & $56.79 \pm 31.17$ & $53.50,60.09$ & $0.1,99.6$ & 0.001 \\
WHtR & $0.47 \pm 0.07$ & $0.46,0.47$ & $0.33-0.77$ & $0.45 \pm 0.06$ & $0.45,0.46$ & $0.35-0.71$ & 0.010 \\
WC (cm) & $72.94 \pm 11.10$ & $72.17,73.71$ & $50.0-119.0$ & $70.64 \pm 10.77$ & $69.50,71.77$ & $52.0-115.5$ & 0.117 \\
HC (cm) & $92.05 \pm 13.23$ & $91.13,92.97$ & $53.0-136.5$ & $85.05 \pm 11.87$ & $85.79,88.30$ & $49.4-128.0$ & 0.001 \\
Neck (cm) & $29.9 \pm 2.32$ & $29.70,30.11$ & $23.5-42.5$ & $29.97 \pm 2.57$ & $29.67,30.27$ & $22.5-38.0$ & 0.342 \\
MUAC (cm) & $24.54 \pm 4.44$ & $24.14,24.94$ & $12.5-43.5$ & $23.14 \pm 4.89$ & $22.58,23.17$ & $13.0-35.7$ & 0.001 \\
\hline
\end{tabular}

CI: confidence interval, HC: hip circumference, MUAC: mid-upper arm circumference, NC: neck circumference, WC: waist circumference, WHtR: waist-to-height ratio, pBMI: body mass index percentile.

The prevalence of obesity based on pBMI was $15.5 \%$ (16.7\% of females and $12.6 \%$ of males). There was no difference in the prevalence of obesity between females and males $\left(\chi^{2}=3.06, p=0.80\right)$. Based on $\mathrm{WHtR}, 25.3 \%$ of children $(27.3 \%$ of females and $20.7 \%$ of males) had obesity. According to WHtR, obesity was more frequent in female than in male adolescents $\left(\chi^{2}=5.54, p=0.019\right.$, Table 2$)$. As shown in Table 3, the prevalence of obesity was highest in the group of 16-year-old adolescents (24.6\%) and lowest $(10.7 \%)$ in 12-year-old adolescents. The prevalence of overweight status was $16.3 \%$ and was higher in females $(17.3 \%)$ than in males $(13.8 \%)$. Moreover, overweight status was highest in 15 -year-old children (23.5\%) and lowest in 12-year-old children (11.2\%, Table 3).

Table 2. Prevalence of obesity based on WHtR and BMI percentiles.

\begin{tabular}{|c|c|c|c|c|}
\hline$n(\%)$ & Category & $\begin{array}{l}\text { Cohort } \\
1144(\%)\end{array}$ & $\begin{array}{l}\text { Female } \\
796(\%)\end{array}$ & $\begin{array}{l}\text { Male } \\
348(\%)\end{array}$ \\
\hline \multirow[t]{2}{*}{ WHtR } & Non-obese & $855(74.7)$ & 579 (72.7) & $276(79.3)$ \\
\hline & Obese & $289(25.3)$ & 217 (27.3) & 72 (20.7) \\
\hline \multirow[t]{2}{*}{ pBMI } & Non-obese & 967 (84.5) & $663(83.3)$ & $308(87.4)$ \\
\hline & Obese & 177 (15.5) & 133 (16.7) & 44 (12.6) \\
\hline
\end{tabular}

WHtR: waist-to-height ratio, pBMI: body mass index percentile.

The sensitivity and specificity of pBMI using WHtR as reference were assessed. Regardless of sex, pBMI presented a low sensitivity (54.0\%), with a high specificity $(97.5 \%)$ in the cohort. pBMI was more sensitive in identifying obesity in males $(56.97 \%)$ than in females $(53.0 \%)$ and more specific in identifying males without obesity $(98.9 \%)$ than females $(96.9 \%$, Table 4$)$. 
Table 3. Body weight classification by BMI percentile split by age and sex.

\begin{tabular}{llllll}
\hline $\boldsymbol{n}(\%)$ & Underweight & Normal Weight & Overweight & Obese & Total \\
\hline Sex & & & & & \\
Female & $17(2.1)$ & $508(63.8)$ & $138(17.3)$ & $133(16.7)$ & 796 \\
Male & $20(5.7)$ & $236(67.8)$ & $48(13.8)$ & $44(12.6)$ & 348 \\
Cohort (total) & $37(3.2)$ & $744(65.0)$ & $186(16.3)$ & $177(15.5)$ & 1144 \\
Age & & & & $15(14.9)$ & 101 \\
$\mathbf{1 1}$ & $6(5.9)$ & $59(58.4)$ & $21(20.8)$ & $23(10.7)$ & 214 \\
$\mathbf{1 2}$ & $12(5.6)$ & $155(72.4)$ & $24(11.2)$ & $40(14.3)$ & 280 \\
$\mathbf{1 3}$ & $9(3.2)$ & $193(68.9)$ & $38(13.6)$ & $31(17.1)$ & 181 \\
$\mathbf{1 4}$ & $4(2.2)$ & $119(65.7)$ & $27(14.9)$ & $24(14.5)$ & 166 \\
$\mathbf{1 5}$ & $5(3.0)$ & $98(59.0)$ & $39(23.5)$ & $35(24.6)$ & 142 \\
$\mathbf{1 6}$ & $1(0.7)$ & $83(58.5)$ & $23(16.2)$ & $9(15.0)$ & 60 \\
$\mathbf{1 7}$ & $0(0.0)$ & $37(61.7)$ & $14(23.3)$ & $177(15.5)$ & 1144 \\
Cohort (total) & $37(3.2)$ & $744(65.0)$ & $186(16.3)$ & & \\
\hline
\end{tabular}

Table 4. Sensitivity and specificity of BMI percentile in screening obesity using WHtR as reference.

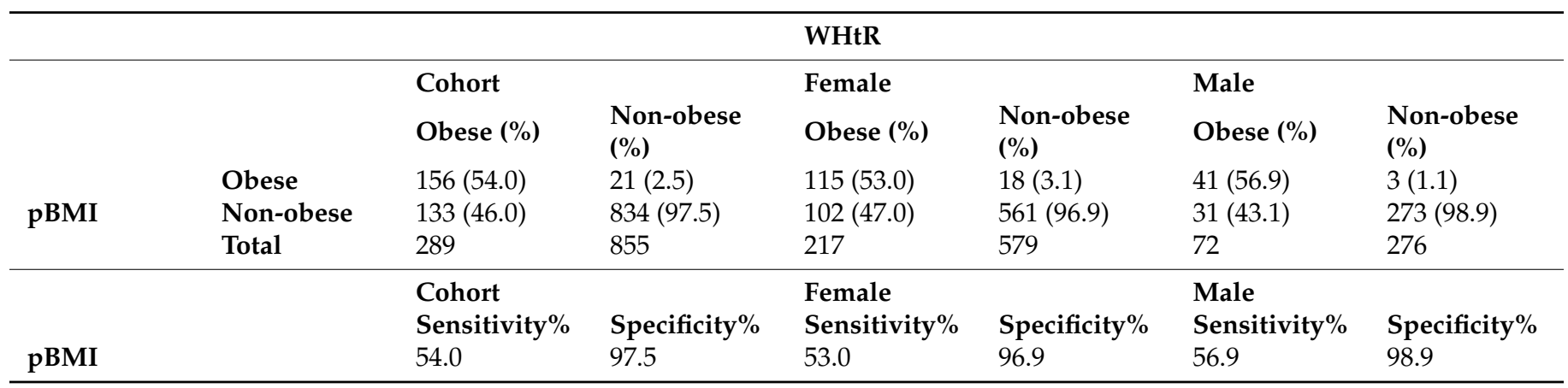

WHtR: waist-to-height ratio, pBMI: body mass index percentile.

The ROC curve for pBMI, WC, HC, NC and MUAC using WHtR as reference, illustrated in Figure 1, showed that WC was the best indicator for obesity, having the largest AUC with high sensitivity and specificity in both males and females and in the cohort. This was followed by pBMI and HC, while NC was the poorest indicator (with the smallest AUC) in the cohort (Figure 1a), as well as in females and males separately (Figure 1b,c, respectively). The cut-offs, sensitivity, specificity and AUC for all anthropometric parameters using WHtR as reference are summarised in Table 5. The optimal cut-offs for obesity by $\mathrm{NC}, \mathrm{MUAC}, \mathrm{WC}, \mathrm{HC}$ and pBMI in the cohort were $30.6 \mathrm{~cm}, 25.9 \mathrm{~cm}, 75.1 \mathrm{~cm}, 92.15 \mathrm{~cm}$ and p85.2 ${ }^{\text {th }}$, respectively, when WHtR was used as reference. The cut-offs for WC and pBMI were slightly higher in females than in males, while the cut-off for NC, MUAC and HC was higher in males than in females. The obtained pBMI cut-off at p95th percentile showed a smaller sensitivity and higher specificity compared to the pBMI at p85.2th percentile in the study.

Table 5. Optimal cut-off, sensitivity, specificity, SE and area under the ROC curves for anthropometric indices in predicting obesity in males, females and cohort using WHtR.

\begin{tabular}{|c|c|c|c|c|c|c|}
\hline & Cut-off & Sensitivity\% & Specificity\% & AUC & SE & $95 \% \mathrm{CI}$ \\
\hline \multicolumn{7}{|l|}{ Cohort } \\
\hline NC & 30.6 & 71.3 & 77.6 & 0.786 & 0.021 & $0.745-0.827$ \\
\hline MUAC & 25.9 & 80.3 & 79.8 & 0.813 & 0.026 & $0.762-0.865$ \\
\hline WC & 75.1 & 90.4 & 89.4 & 0.982 & 0.004 & 0.974-0.991 \\
\hline $\mathrm{HC}$ & 92.15 & 80.3 & 84.7 & 0.883 & 0.018 & $0.848-0.917$ \\
\hline pBMI & 85.2 & 87.9 & 88.9 & 0.947 & 0.010 & $0.927-0.967$ \\
\hline pBMIr & 95.1 & 57.3 & 98.3 & 0.947 & 0.010 & $0.927-0.967$ \\
\hline
\end{tabular}


Table 5. Cont.

\begin{tabular}{|c|c|c|c|c|c|c|}
\hline & Cut-off & Sensitivity $\%$ & Specificity\% & AUC & SE & $95 \%$ CI \\
\hline \multicolumn{7}{|l|}{ Female } \\
\hline NC & 30.70 & 72.2 & 77.9 & 0.801 & 0.025 & $0.752-0.851$ \\
\hline MUAC & 25.55 & 85.6 & 76.3 & 0.853 & 0.028 & $0.798-0.908$ \\
\hline WC & 76.1 & 91.8 & 95.4 & 0.982 & 0.006 & 0.970-0.994 \\
\hline $\mathrm{HC}$ & 90.25 & 85.6 & 75.7 & 0.864 & 0.024 & $0.817-0.912$ \\
\hline pBMI & 84.45 & 90.7 & 87.2 & 0.947 & 0.013 & $0.922-0.972$ \\
\hline pBMIr & 95.1 & 56.7 & 98.1 & 0.947 & 0.013 & $0.922-0.972$ \\
\hline \multicolumn{7}{|l|}{ Male } \\
\hline NC & 30.6 & 70.0 & 85.4 & 0.764 & 0.037 & $0.691-0.837$ \\
\hline MUAC & 25.90 & 71.7 & 85.0 & 0.749 & 0.050 & $0.650-0.847$ \\
\hline WC & 73.25 & 95.0 & 91.2 & 0.985 & 0.006 & $0.973-0.996$ \\
\hline $\mathrm{HC}$ & 93.50 & 78.3 & 93.0 & 0.915 & 0.025 & $0.867-0.963$ \\
\hline pBMI & 80.75 & 90.0 & 87.2 & 0.946 & 0.017 & $0.913-0.980$ \\
\hline pBMIr & 95.0 & 58.3 & 98.7 & 0.946 & 0.017 & $0.913-0.980$ \\
\hline
\end{tabular}

AUC: area under the curve, SE: standard error, CI: confidence interval, HC: hip circumference, MUAC: mid-upper arm circumference, NC: neck circumference, WC: waist circumference, WHtR: waist-to-height ratio, pBMI: body mass index percentile, pBMIr: recommended body mass index percentile.

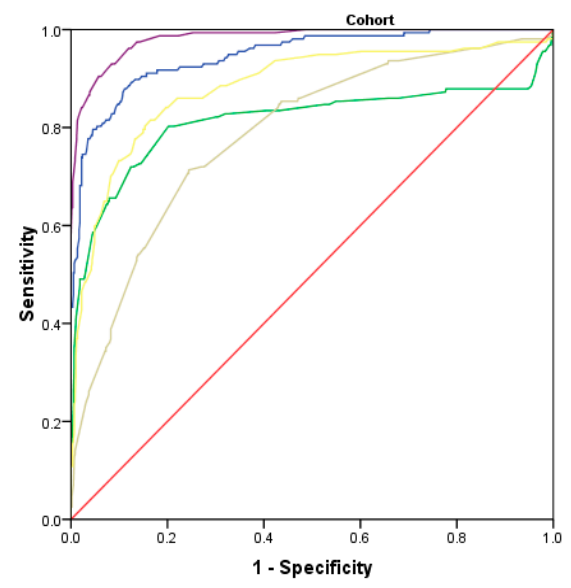

(a)

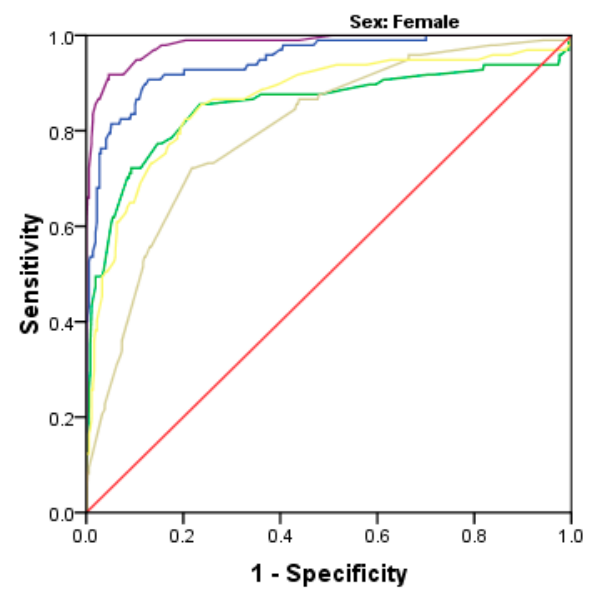

(b)
Source of the Curve

二BM\%

- Neck

- Re
Source of the Curve

- $\mathrm{BMI} \%$

- MUAC

Neck

$\mathrm{HC}$

- Reference Line

Figure 1. Cont. 


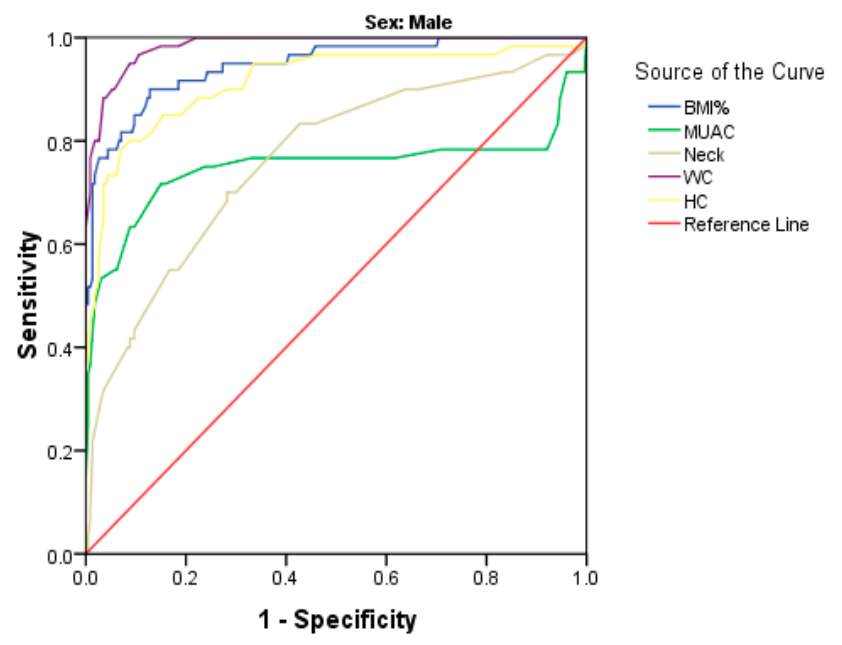

(c)

Figure 1. Receiver operating characteristic (ROC) curves for anthropometric measures using WHtR as reference in the cohort, females and males $(\mathbf{a}-\mathbf{c})$.

Figure 2 shows the ROC curve for WHtR, WC, HC, NC and MUAC using pBMI as reference, while the cut-off, sensitivity, specificity and AUC for all the anthropometric parameters are summarised in Table 6. The results showed that WHtR was the best indicator for obesity, having the largest AUC and highest sensitivity in the cohort (Figure 2a) as well as in females (Figure 2b) and males (Figure 2c), separately. This was followed by WC and $\mathrm{HC}$, then MUAC in the cohort as well as in females and males. NC was the poorest indicator (with the smallest AUC) in the cohort as well as in males and females (Figure 2a-c).

Table 6. Optimal cut-off, sensitivity, specificity, SE and area under the ROC curves for anthropometric indices in predicting obesity in males, females and cohort using pBMI.

\begin{tabular}{|c|c|c|c|c|c|c|}
\hline & Cut-off & Sensitivity\% & Specificity\% & AUC & SE & $95 \%$ CI \\
\hline \multicolumn{7}{|l|}{ Cohort } \\
\hline WHtR & 0.481 & 97.0 & 84.0 & 0.966 & 0.007 & $0.952-0.980$ \\
\hline NC & 30.95 & 82.2 & 73.4 & 0.837 & 0.023 & $0.793-0.882$ \\
\hline MUAC & 27.95 & 85.1 & 90.8 & 0.909 & 0.023 & $0.864-0.955$ \\
\hline WC & 76.1 & 91.1 & 89.3 & 0.965 & 0.008 & $0.949-0.980$ \\
\hline $\mathrm{HC}$ & 95.75 & 90.1 & 87.1 & 0.934 & 0.017 & $0.900-0.968$ \\
\hline \multicolumn{7}{|l|}{ Female } \\
\hline WHtR & 0.484 & 96.8 & 84.1 & 0.965 & 0.008 & 0.949-0.981 \\
\hline NC & 30.95 & 84.1 & 95.6 & 0.846 & 0.026 & $0.795-0.897$ \\
\hline MUAC & 27.95 & 93.7 & 89.8 & 0.851 & 0.017 & $0.920-0.985$ \\
\hline WC & 76.1 & 92.1 & 87.6 & 0.966 & 0.008 & $0.949-0.982$ \\
\hline $\mathrm{HC}$ & 95.25 & 90.5 & 83.4 & 0.922 & 0.023 & $0.877-0.967$ \\
\hline \multicolumn{7}{|l|}{ Male } \\
\hline WHtR & 0.491 & 97.4 & 88.8 & 0.968 & 0.014 & 0.940-0.995 \\
\hline NC & 31.85 & 71.1 & 82.5 & 0.827 & 0.042 & $0.745-0.909$ \\
\hline MUAC & 25.9 & 84.2 & 82.1 & 0.842 & 0.052 & $0.740-0.944$ \\
\hline WC & 75.75 & 94.7 & 90.0 & 0.963 & 0.016 & $0.932-0.995$ \\
\hline HC & 96.75 & 89.5 & 93.2 & 0.954 & 0.026 & $0.902-1.006$ \\
\hline
\end{tabular}

AUC: area under the curve, SE: standard error, CI: confidence interval, HC: hip circumference, MUAC: mid-upper arm circumference, NC: neck circumference, WC: waist circumference, WHtR: waist-to-height ratio, pBMI: body mass index percentile. 


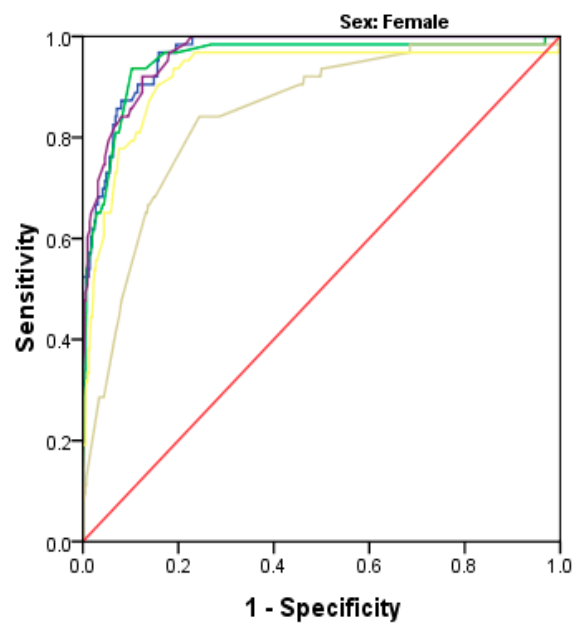

Source of the Curve

$$
\text { - WHAR }
$$

- MUAC

- Neck

-WC

$\mathrm{HC}$
- Reference Line

(a)

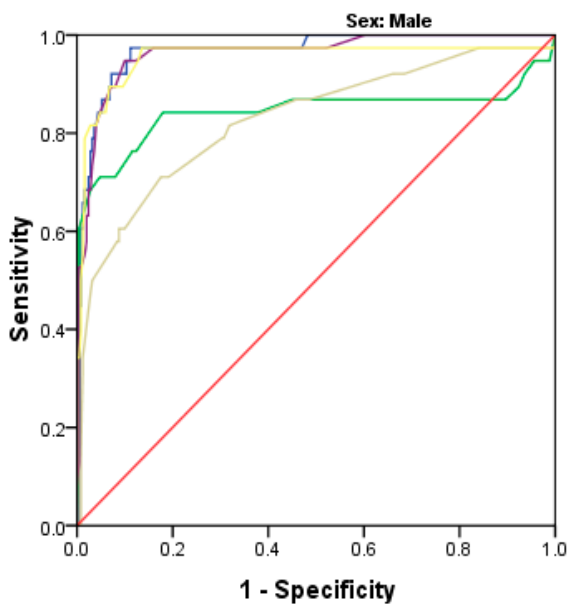

Source of the Curve

$$
\begin{aligned}
& \text { - WHAR } \\
& \text { - MUAC }
\end{aligned}
$$

- MUAC

- Neck

HC

- Reference Line

(b)

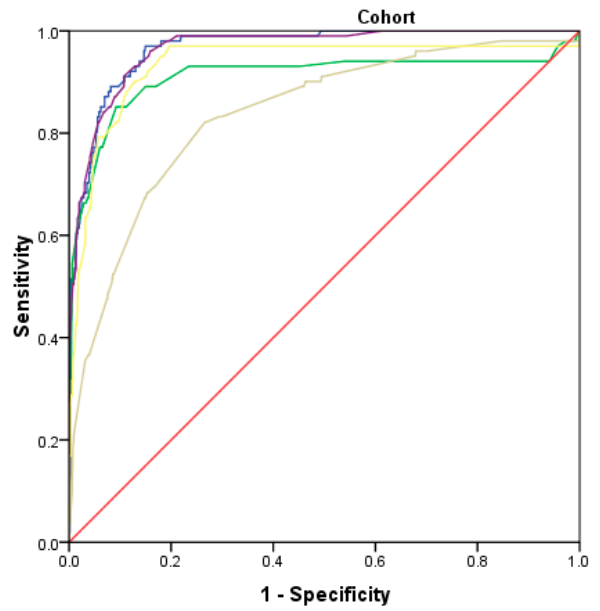

Source of the Curve

二 $\begin{aligned} & \text { MHAR } \\ & \text { MUAC }\end{aligned}$

- MUAC
二 Neck
- WC $_{\text {HC }}$

- Reference Line

(c)

Figure 2. Receiver operating characteristic (ROC) curves for anthropometric measures using pBMI as reference in the cohort, females and males $(\mathbf{a}-\mathbf{c})$.

Using pBMI as reference, the optimal cut-offs for obesity for WHtR, NC, MUAC, WC and $\mathrm{HC}$ in the cohort were $0.481,30.95 \mathrm{~cm}, 27.95 \mathrm{~cm}, 76.1 \mathrm{~cm}$ and $95.75 \mathrm{~cm}$, respectively. A 
similar trend was observed in males and females, except that the cut-offs for WHtR, NC, MUAC, WC and HC were slightly higher in females than in males.

The predicted prevalence of obesity, based on the new cut-offs established from the ROC analysis, is summarised in Table 7 . The predicted prevalence of obesity obtained using cut-offs of the ROC analysis was higher than that of the observed prevalence of obesity in the study. Using WHtR as reference, the predicted prevalence of obesity for NC, MUAC, WC, HC and pBMI ranged from $21.8 \%$ to $38.8 \%$ in the cohort, $19.5 \%$ to $37.2 \%$ in females and $22.1 \%$ to $31.0 \%$ in males. The closest predicted prevalence of obesity comparable to that of WHtR (observed prevalence) was by NC (23.0\%) in the cohort, WC (31.4\%) in females and MUAC (22.1\%) in males. When pBMI was used as reference, the predicted prevalence of obesity ranged from $12.9 \%$ to $32.1 \%$ in the cohort, $12.7 \%$ to $36.4 \%$ in females and $20.7 \%$ to $23.3 \%$ in males. The closest predicted prevalence of obesity comparable to that of pBMI (observed prevalence) was by MUAC $(12.9 \%)$ in the cohort, NC $(19.2 \%)$ in females and NC $(20.7 \%)$ in males. The predicted prevalence using WHtR as reference was higher than that of $\mathrm{pBMI}$ as reference.

Table 7. Predicted prevalence of obesity based on the new cut-off values using WHtR and pBMI.

\begin{tabular}{llll}
\hline & Cohort (\%) & Female (\%) & Male (\%) \\
\hline Ref: WHtR & & & $108(31.0)$ \\
NC & $263(23.0)$ & $155(19.5)$ & $77(22.1)$ \\
MUAC & $249(21.8)$ & $177(22.3)$ & $107(30.7)$ \\
WC & $357(31.2)$ & $250(31.4)$ & $89(25.6)$ \\
HC & $438(38.3)$ & $296(37.2)$ & $105(30.2)$ \\
BMI\% & $352(30.8)$ & $274(34.4)$ & $72(20.7)$ \\
\hline Ref: pBMI & & & $77(22.1)$ \\
NC & $260(22.7)$ & $153(19.2)$ & $81(23.3)$ \\
MUAC & $147(12.9)$ & $101(12.7)$ & $73(21.0)$ \\
WC & $323(28.2)$ & $250(31.4)$ & $73(21.0)$ \\
HC & $367(32.1)$ & $290(36.4)$ & $259(32.5)$ \\
WHtR & $342(29.9)$ & . & \\
\hline
\end{tabular}

Ref: reference, HC: hip circumference, MUAC: mid-upper arm circumference, NC: neck circumference, WC: waist circumference, WHtR: waist-to-height ratio, pBMI: body mass index percentile.

The various anthropometric indices were classified into percentile categories according to age and are summarised in Table 8. All percentiles of the various anthropometric measures (WHtR, pBMI, WC and HC) generally increased with age for all the percentile ranges. At the 95th percentile, WHtR ranged from 0.57 to 0.61 in females and from 0.52 to 0.64 in males. Values of the 95th percentile of WHtR were generally higher than the recommended cut-off of 0.5 . It was at the 85 th percentile in female children aged 11 years and males between 12 and 13 years that had values close to the recommended cut-off of 0.5. For pBMI, the 95th percentile ranged from p95th to p98.14th in females and from p94.0th to p99.07th in males, and the values increased with age. Most of the percentile values for all ages were above the recommended BMI percentile at $\mathrm{p} 95 \mathrm{th}$, which indicates childhood obesity. Moreover, it was the 85th percentile that tallied with the recommended BMI percentile of p95th, especially in females aged 13 to 17 years and in 11- and 14-year-old males. The 95th percentile for WC ranged from $89.6 \mathrm{~cm}$ to $99.7 \mathrm{~cm}$ in females and $92.50 \mathrm{~cm}$ to $102.68 \mathrm{~cm}$ in males. The 95th percentile values for $\mathrm{HC}$ ranged from $106.7 \mathrm{~cm}$ to $124.28 \mathrm{~cm}$ in females and from $105.75 \mathrm{~cm}$ to $115.95 \mathrm{~cm}$ in males. 
Table 8. Percentiles of the various obesity measures in children.

\begin{tabular}{|c|c|c|c|c|c|c|c|c|}
\hline & & & FEMALE & & & MALE & & \\
\hline & WHtR & pBMI & WC & $\mathrm{HC}$ & WHtR & $\mathrm{pBMI}$ & WC & $\mathrm{HC}$ \\
\hline \multicolumn{9}{|l|}{11 yrs } \\
\hline 5 th & 0.386 & 4.80 & 61.00 & 70.15 & 0.382 & 3.80 & 56.00 & 65.00 \\
\hline 25th & 0.421 & 27.40 & 64.75 & 77.75 & 0.413 & 35.60 & 61.00 & 76.00 \\
\hline 50th & 0.452 & 70.20 & 69.00 & 81.00 & 0.445 & 69.50 & 68.00 & 85.00 \\
\hline 75th & 0.494 & 90.50 & 74.50 & 95.00 & 0.507 & 91.80 & 76.00 & 91.00 \\
\hline 85th & 0.519 & 94.70 & 78.55 & 98.20 & 0.542 & 95.40 & 80.00 & 97.00 \\
\hline 95th & 0.571 & 97.90 & 90.25 & 106.70 & 0.636 & 98.60 & 98.00 & 109.00 \\
\hline \multicolumn{9}{|l|}{12 yrs } \\
\hline 5 th & 0.376 & 5.30 & 57.00 & 72.00 & 0.378 & 1.40 & 57.00 & 70.00 \\
\hline 25th & 0.410 & 27.80 & 62.00 & 75.88 & 0.413 & 34.10 & 62.00 & 76.25 \\
\hline 50th & 0.435 & 53.20 & 66.00 & 84.00 & 0.437 & 54.00 & 65.00 & 83.50 \\
\hline 75th & 0.482 & 82.90 & 73.25 & 91.00 & 0.478 & 81.90 & 72.00 & 91.75 \\
\hline 85th & 0.521 & 93.22 & 81.00 & 97.35 & 0.506 & 93.14 & 78.00 & 98.25 \\
\hline 95th & 0.610 & 98.18 & 97.45 & 110.25 & 0.596 & 98.68 & 92.50 & 105.75 \\
\hline \multicolumn{9}{|l|}{13 yrs } \\
\hline 5 th & 0.377 & 6.56 & 56.90 & 70.75 & 0.382 & 8.71 & 58.00 & 70.24 \\
\hline 25th & 0.412 & 39.55 & 63.00 & 78.38 & 0.409 & 27.90 & 62.00 & 78.00 \\
\hline 50th & 0.448 & 68.40 & 68.00 & 85.00 & 0.439 & 61.80 & 67.00 & 83.00 \\
\hline 75th & 0.485 & 90.15 & 75.00 & 96.13 & 0.471 & 87.10 & 74.25 & 92.25 \\
\hline 85th & 0.531 & 95.00 & 81.60 & 101.88 & 0.518 & 92.11 & 81.00 & 98.10 \\
\hline 95th & 0.583 & 97.83 & 89.60 & 108.25 & 0.605 & 98.94 & 92.70 & 111.70 \\
\hline \multicolumn{9}{|l|}{14 yrs } \\
\hline 5 th & 0.368 & 8.49 & 58.05 & 75.15 & 0.382 & 10.45 & 60.20 & 69.60 \\
\hline 25th & 0.413 & 47.25 & 65.00 & 85.00 & 0.409 & 34.00 & 65.25 & 81.00 \\
\hline 50th & 0.451 & 69.05 & 71.00 & 90.25 & 0.433 & 62.20 & 70.00 & 84.00 \\
\hline 75th & 0.505 & 92.45 & 79.25 & 99.00 & 0.501 & 90.15 & 74.50 & 93.50 \\
\hline 85th & 0.528 & 95.00 & 84.00 & 104.00 & 0.522 & 95.21 & 83.75 & 101.49 \\
\hline 95th & 0.595 & 97.59 & 90.98 & 112.00 & 0.596 & 99.07 & 94.95 & 115.95 \\
\hline \multicolumn{9}{|l|}{15 yrs } \\
\hline 5th & 0.379 & 14.93 & 60.90 & 79.00 & 0.357 & 0.25 & 57.75 & 67.00 \\
\hline 25th & 0.421 & 52.25 & 67.00 & 88.00 & 0.379 & 19.10 & 62.50 & 80.00 \\
\hline 50th & 0.460 & 79.05 & 74.00 & 95.00 & 0.422 & 54.40 & 70.00 & 85.00 \\
\hline 75th & 0.505 & 91.68 & 81.50 & 104.25 & 0.461 & 78.75 & 75.85 & 94.35 \\
\hline 85th & 0.543 & 95.00 & 85.54 & 109.60 & 0.532 & 91.85 & 84.00 & 100.50 \\
\hline 95th & 0.596 & 95.41 & 97.70 & 119.10 & 0.581 & 98.10 & 97.25 & 112.65 \\
\hline \multicolumn{9}{|l|}{16 yrs } \\
\hline 5 th & 0.388 & 11.73 & 63.25 & 83.00 & 0.381 & 5.50 & 64.47 & 79.93 \\
\hline 25th & 0.433 & 62.25 & 71.13 & 91.00 & 0.403 & 30.30 & 67.75 & 84.00 \\
\hline 50th & 0.481 & 83.00 & 76.70 & 100.75 & 0.421 & 63.00 & 72.00 & 89.00 \\
\hline 75th & 0.537 & 95.00 & 84.00 & 111.90 & 0.473 & 85.50 & 80.00 & 98.50 \\
\hline 85th & 0.563 & 95.00 & 92.00 & 116.00 & 0.515 & 93.60 & 87.38 & 105.38 \\
\hline 95th & 0.609 & 96.98 & 97.38 & 124.85 & 0.599 & 97.76 & 102.68 & 115.35 \\
\hline \multicolumn{9}{|l|}{$17 \mathrm{yrs}$} \\
\hline 5th & 0.396 & 14.30 & 65.45 & 85.45 & 0.379 & 5.00 & 67.00 & 81.00 \\
\hline 25th & 0.443 & 62.50 & 71.63 & 90.25 & 0.412 & 26.00 & 69.25 & 88.15 \\
\hline 50th & 0.475 & 81.50 & 76.00 & 99.50 & 0.425 & 57.50 & 73.75 & 91.75 \\
\hline 75th & 0.526 & 92.75 & 84.75 & 106.00 & 0.477 & 79.75 & 83.75 & 102.75 \\
\hline 85th & 0.562 & 95.00 & 87.33 & 109.83 & 0.514 & 93.05 & 89.15 & 108.70 \\
\hline 95th & 0.608 & 95.00 & 93.10 & 122.37 & 0.519 & 94.00 & 92.00 & 112.50 \\
\hline
\end{tabular}

HC: hip circumference, WC: waist circumference, WHtR: waist-to-height ratio, pBMI: body mass index percentile.

\section{Discussion}

The increasing prevalence of obesity in South African children [38] presents a major public health concern, with the odds of increased CVD risk in adulthood [39]. Assessment of obesity in South African children and adolescents relies on the WHO [24], CDC [25] or IOTF [26] recommended cut-off values for BMI percentile, as well as the accepted cut-off for WHtR [27], mainly derived from Caucasian populations, which did not take into con- 
sideration genetic, ethnic and growth pattern differences existing in different populations. It was therefore necessary to assess anthropometric measures for screening obesity in order to establish cut-off values specific to this South African adolescent population. Applying the recommended $\mathrm{pBMI}(\mathrm{r})$ cut-off score at $95^{\text {th }}$ percentile and $\mathrm{WHtR}$ at 0.5 , the prevalence of obesity was $15.5 \%$ and $25.3 \%$, respectively. We used WHtR as the reference method for assessing the effectiveness of pBMI to screen obesity, as WHtR has previously been reported to be a better indicator than pBMI in assessing obesity in children [40]. Based on WHtR as reference, $\mathrm{pBMI}$ was less sensitive (54.0\%) to identifying obesity but was highly specific $(97.5 \%)$ in discriminating non-obese adolescents in the population. This finding corroborates previous studies that have shown low sensitivity of pBMI in screening obesity in Ghanaian children when percentage of body fat was used as reference [41].

ROC analysis for assessing anthropometric measures showed WC as the best indicator for obesity, followed by pBMI and HC, when WHtR was used as reference. As such, the optimal cut-off values for identifying obesity by NC, MUAC, WC, HC and pBMI in the cohort were $30.6 \mathrm{~cm}, 25.9 \mathrm{~cm}, 75.1 \mathrm{~cm}, 92.15 \mathrm{~cm}$ and p85.2th, respectively. On the other hand, WHtR was the best indicator for obesity, followed by WC and HC, when pBMI was used as reference. Thus, the optimal cut-offs for obesity by WHtR, NC, MUAC, WC and $\mathrm{HC}$ in the cohort were $0.481,30.95 \mathrm{~cm}, 27.95 \mathrm{~cm}, 76.1 \mathrm{~cm}$ and $95.75 \mathrm{~cm}$, respectively, in the cohort. The observed cut-off score for WHtR $(0.481)$ in the cohort was slightly different but close to the recommended standard of 0.5 , particularly in males (0.49), but also females (0.484). This suggests that the recommended cut-off score of 0.5 for WHtR may not be affected by ethnicity in screening obesity. This finding supports previous studies, which have shown that WHtR is less affected by sex or ethnicity [42], as similar cut-off values have been observed in different ethnic populations [43,44]. Moreover, a previous study by Matsha et al. in 2013 [45] in South African children aged 10-16 years showed a WHtR cut-off of 0.465 , lower than the recommended 0.5 cut-off and the scores of this study (0.481). The steady increase of the prevalence of obesity in South African children and adolescents reported may have resulted in a higher cut-off value for WHtR. Therefore, routine assessments of obesity indicators at different time points may be necessary.

Furthermore, a lower cut-off value of p85.2th (p84.45th for females and p80.75th for males) with improved sensitivity $(87.9 \%)$ was observed for $\mathrm{pBMI}$. This value is considerably different from the CDC recommended cut-off score of p95th for obesity in children and adolescents. A previous study equally showed a lower cut-off for pBMI in Chinese children [46], which was also different from the CDC cut-off value. The present study suggests that the CDC recommended BMI percentile (p95th) cut-off value for the diagnosis of (or classifying) obesity in children may not account for gender, ethnic and genetic differences. BMI percentile has been suggested to be affected by body composition in children, as the distribution of fat mass and fat-free mass is highly variable and affected by age and pubertal maturation, wherein adiposity may be linked with advanced puberty in girls [47]. Postnatal linear growth pattern for weight and height is controlled by genetic, nutrition and endocrine factors that may influence the onset of puberty [48]. A study in South Africa, which assessed body composition and abdominal adiposity from birth to age 22, showed that relative linear growth was associated with fat mass as well as abdominal, visceral and subcutaneous adipose tissues in children $0-8$ years and 19-22 years but showed no association in the adolescent age group (8-18 years) [34]. This implies that at adolescence there is variability of body composition, confirming the influence of puberty on the linear growth pattern. Moreover, epidemiological reports have suggested that the timing of pubertal onset may be a key determinant of cardio-metabolic health in adolescence and adulthood, and there may exist racial and ethnic disparities of puberty onset timing [49]. Considering that puberty onset commences at adolescence, the disparity of pBMI cut-off obtained in this study to that of CDC cut-off may be accounted for by puberty, genetic and ethnic differences.

Among the other anthropometric measures (WC, NC, MUAC and HC), WC showed a high sensitivity and specificity and could be an alternative and feasible method to screen 
obesity in adolescents, applying a proposed cut-off range of between 75.1 and $76.1 \mathrm{~cm}$, which was higher in females than in males. Previous studies have suggested WC to be a good indicator for obesity screening in children $[50,51]$. However, there is no recommended cut-off score for WC in the assessment of obesity in children. Therefore, the suggested cut-off value may be used in conjunction with WHtR and/or pBMI indicators. In an Iranian study, NC was shown to be a useful indicator in screening obesity in children and adolescents, with cut-off values of 27.5-38.3 cm for males and 26.7-33.4 cm for females [52]. In the present study, NC was shown to have the lowest sensitivity and thus was a poor indicator for screening obesity in adolescents and showed cut-off values ranging between 30.6 and $31.85 \mathrm{~cm}$, slightly higher in males. The cut-off scores, however, fall within the range of other previous studies in children, as reported by Teheri et al. [52] MUAC has been reported as a possible tool for screening obesity [53] in children. In the present study, MUAC was not a good indicator for obesity. The cut-off observed in this study ranged from 25.55 to $27.75 \mathrm{~cm}$. This finding concords with a 12-country study reporting an approximately $25 \mathrm{~cm}$ cut-off value for MUAC in both boys and girls aged 9-11 years and was country-specific, with South African boys presenting a cut-off of $23.2 \mathrm{~cm}$ [54]. A lower cut-off for MUAC between 16.38 and $22.73 \mathrm{~cm}$ was observed in Pakistani children aged 5-14 years [55]. Moreover, MUAC has been shown to be appropriate in screening overweight status in children younger than 2 years of age in a South African population with a high sensitivity and specificity [56]. However, the sensitivity of MUAC in the present study was relatively low and thus not a good indicator to screen obesity in this population. HC has rarely been used as an indicator for obesity, as it has mostly been used to determine waist-to-hip ratio (WHR), which is a good indicator for obesity in adults. We established cut-off values ranging from 92.15 to $96.75 \mathrm{~cm}$, though HC showed a low sensitivity compared to pBMI, WHtR and WC. Interestingly, its sensitivity was higher than that of MUAC and NC. This result is therefore indicative of a possible usefulness of $\mathrm{HC}$ to screen obesity in children. However, this will require several studies to assess $\mathrm{HC}$ for obesity screening in order to develop recommended cut-off values in male and female children.

With regards to age-wise percentile distribution for the anthropometric measures as presented in Table 8, percentiles increased with age and differed between male and female children. The 95th percentile of all the anthropometric indices presented values that were above the established cut-offs for the various anthropometric indicators. Moreover, it was in the 85th percentile for WHtR that values were comparable to the 0.5 cut-off for most age groups in both males and females. For pBMI, the 95th percentile showed values above the p95th cut-off for all age groups, while it was the 85th percentile that showed values similar to the p95th cut-off for some age groups. This finding suggests that values at the 85th percentile may be a suitable indicator for obesity for the various anthropometric indices.

This is the first study to assess obesity indicators for South African adolescents of African ancestry. This study has shown that the established pBMI cut-off in this population was different from the CDC recommended cut-off. Thus, the CDC cut-off value $\mathrm{pBMI}$ may be affected by race and ethnic differences in adolescents. However, the findings of this study may be limited, in that it did not use a reference method for the direct quantification of body fat but relied on WHtR as a reference method, which depends on central adiposity for assessing obesity in children and has been shown to be a better indicator than pBMI. Moreover, our study did not assess other cardiometabolic disease risk factors, such as dyslipidaemia, hypertension and insulin resistance, which are associated with obesity and may associate differently with anthropometric measures in different populations. More so, this study constituted South African adolescents of African ancestry who are predominately of the Xhosa ethnicity and therefore did not include other ethnic populations in South Africa. Hence, the findings may be limited to a generalization of the entire South African adolescent population. 


\section{Conclusions}

This study reveals a lower pBMI cut-off value, different from the CDC recommended cut-off, for screening obesity in a South African adolescent population. This study has established that the optimal pBMI cut-off for obesity screening may be ethnic-specific. This study was limited to South Africans of African ancestry predominately of the Xhosa ethnic group. Therefore, future studies involving other ethnic populations with larger sample sizes are recommended to provide national representative data for the South African adolescent population.

Author Contributions: Conceptualization, B.N.N.-C. and N.G.; data curation, B.N.N.-C., C.A., B.P.L., P.C.A., M.M.M., G.A.E. and K.S.-Z.; formal analysis, G.A.E. and K.S.-Z.; funding acquisition, B.N.N.-C.; investigation, C.A., B.P.L., P.C.A. and M.M.M.; methodology, B.N.N.-C., C.A. and N.G.; supervision, C.R.S.-R. and B.N.N.-C. validation, G.A.E., K.S.-Z., C.R.S.-R., B.N.N.-C. and N.G.; writing—original draft, B.N.N.-C. and G.A.E.; writing—review and editing, K.S.-Z., G.A.E., B.N.N.-C. and N.G. All authors have read and agreed to the published version of the manuscript.

Funding: This work was supported by the South African National Research Foundation fund (Grant number 106151) and the Medical Research Council Self Initiate Research Grant to Benedicta N. Nkeh-Chungag. The funding source has no role in the collection, analysis or interpretation of the data or in the decision to submit the manuscript for publication.

Institutional Review Board Statement: The study was conducted according to the guidelines of the Declaration of Helsinki. Ethical clearance was obtained from the Health Sciences Ethics Committee of Walter Sisulu University (Ref No: 112/2018) and the University of Fort Hare (CH1011SCHU01), South Africa.

Informed Consent Statement: Informed consent was obtained from all subjects involved in the study.

Data Availability Statement: All the data for this study have been summarised in the results. According to the South Africa National Data Protection Act, all of the participant's data are kept confidential and may be available upon reasonable request.

Acknowledgments: We wish to thank the administration of all the schools for permitting our research group to conduct this study. We are equally thankful to all the parents/guardians that granted us consent for their children to participate in this study.

Conflicts of Interest: The authors declare no conflict of interest.

\section{References}

1. Di Cesare, M.; Sorić, M.; Bovet, P.; Miranda, J.J.; Bhutta, Z.; Stevens, G.A.; Laxmaiah, A.; Kengne, A.P.; Bentham, J. The epidemiological burden of obesity in childhood: A worldwide epidemic requiring urgent action. BMC Med. 2019, 17, 212. [CrossRef] [PubMed]

2. Development Initiatives. 2018 Global Nutrition Report: Shining a Light to Spur Action on Nutrition. Development Initiatives Poverty Research Ltd.: Bristol, UK, 2018; Available online: https:/ /globalnutritionreport.org/ (accessed on 2 April 2019).

3. Lobstein, T.; Jackson-Leach, R.; Moodie, M.L.; Hall, K.D.; Gortmaker, S.L.; Swinburn, B.A. Child and adolescent obesity: Part of a bigger picture. Lancet 2015, 385, 2510-2520. [CrossRef]

4. Friedemann, C.; Heneghan, C.; Mahtani, K.; Thompson, M.; Perera, R.; Ward, A.M. Cardiovascular disease risk in healthy children and its association with body mass index: Systematic review and meta-analysis. BMJ 2012, 345, e4759. [CrossRef] [PubMed]

5. Nkeh-Chungag, B.N.; Sekokotla, A.M.; Sewani-Rusike, C.; Namugowa, A.; Iputo, E. Prevalence of hypertension and prehypertension in 13-17 year old adolescents living in Mthatha-South Africa: A cross-sectional. Cent. Eur. J. Public Health 2015, $23,59-64$. [CrossRef]

6. Matjuda, E.N.; Engwa, G.A.; Anye, S.N.C.; Nkeh-Chungag, B.N.; Goswami, N. Cardiovascular Risk Factors and Their Relationship with Vascular Dysfunction in South African Children of African Ancestry. J. Clin. Med. 2021, 10, 354. [CrossRef] [PubMed]

7. Cook, S.; Kavey, R.E. Dyslipidemia and pediatric obesity. Pediatr. Clin. Nutr. Am. 2011, 58, 1363-1373. [CrossRef]

8. Brady, T.M. Obesity-related hypertension in children. Front. Pediatr. 2017, 5, 197. [CrossRef]

9. Matjuda, E.N.; Sewani-Rusike, C.R.; Anye, S.N.C.; Engwa, G.A.; Nkeh-Chungag, B.N. Relationship between High Blood Pressure and Microalbuminuria in Children Aged 6-9 Years in a South African Population. Children 2020, 7, 131. [CrossRef]

10. Pulgaron, E.R.; Delamater, A.M. Obesity and type 2 diabetes in children: Epidemiology and treatment. Curr. Diab. Rep. 2014, 14, 508. [CrossRef] 
11. Kodama, S.; Horikawa, C.; Fujihara, K.; Heianza, Y.; Hirasawa, R.; Yachi, T. Comparisons of the strength of associations with future type 2 diabetes risk among anthropometric obesity indicators, including waist-to-height ratio: A meta-analysis. Am. J. Epidemiol. 2012, 176, 959-969. [CrossRef]

12. Raj, M. Obesity and cardiovascular risk in children and adolescents. Indian J. Endocr. Metab. 2012, 16, 13-19. [CrossRef]

13. Krul, M.; van der Wouden, J.C.; Schellevis, F.G.; van Suijlekom-Smit, L.W.A.; Koes, B.W. Musculoskeletal problems in overweight and obese children. Ann. Fam. Med. 2009, 7, 352-356. [CrossRef]

14. Park, M.H.; Falconer, C.; Viner, R.M.; Kinra, S. The impact of childhood obesity on morbidity and mortality in adulthood: A systematic review. Obes. Rev. 2012, 13, 985-1000. [CrossRef]

15. Krebs, N.F.; Himes, J.H.; Jacobson, D.; Nicklas, T.A.; Guilday, P.; Styne, D. Assessment of Child and Adolescent Overweight and Obesity. Pediatr. 2007, 120, S193. [CrossRef] [PubMed]

16. Santomauro, F.; Lorini, C.; Pieralli, F.; Niccolai, G.; Picciolli, P.; Vezzosi, S.; Bonaccorsi, G. Waist-to-height ratio and its associations with body mass index in a sample of Tuscan children in primary school. Ital. J. Pediatr. 2017, 43, 53. [CrossRef] [PubMed]

17. De Almeida, C.A.; Del Ciampo, L.A.; Ricco, R.G.; Silva, S.M.; Naves, R.B.; Pina, J.F. Assessment of mid-upper arm circumference as a method for obesity screening in preschool children. J. Pediatr. 2003, 79, 455-460. [CrossRef]

18. Nafiu, O.O.; Burke, C.; Lee, J.; Voepel-Lewis, T.; Malviya, S.; Tremper, K.K. Neck circumference as a screening measure for identifying children with high body mass index. Pediatrics 2010, 126, e306-e310. [CrossRef]

19. Lear, S.A.; James, P.T.; Ko, G.T.; Kumanyika, S. Appropriateness of waist circumference and waist-to-hip ratio cutoffs for different ethnic groups. Eur. J. Clin. Nutr. 2010, 64, 42-61. [CrossRef] [PubMed]

20. Lee, C.M.Y.; Huxley, R.R.; Wildman, R.P.; Woodward, M. Indices of abdominal obesity are better discriminators of cardiovascular risk factors than BMI: A meta-analysis. J. Clin. Epidemiol. 2008, 61, 646-653. [CrossRef]

21. Ashwell, M.; Hsieh, S.D. Six reasons why the waist-to-height ratio is a rapid and effective global indicator for health risks of obesity and how its use could simplify the international public health message on obesity. Int. J. Food Sci. Nutr. 2005, 56, 303-307. [CrossRef] [PubMed]

22. Arnaiz, P.; Grob, F.; Cavada, G.; Domínguez, A.; Bancalari, R.; Cerda, V.; Zamorano, J.; Fernández, M.; García, H. Waist-to-height ratio does not change with gender, age and pubertal stage in elementary school children. Rev. Med. Chile 2014, 142, 574-578. [CrossRef] [PubMed]

23. Sijtsma, A.; Bocca, G.; L'abée, C.; Liem, E.T.; Sauer, P.J.; Corpeleijn, E. Waist-to height ratio, waist circumference and BMI as indicators of percentage fat mass and cardiometabolic risk factors in children aged 3-7 years. Clin. Nutr. 2014, 33, 311-315. [CrossRef]

24. De Onis, M.; Onyango, A.W.; Borghi, E.; Siyam, A.; Nishida, C.; Siekmann, J. Development of a WHO growth reference for school-aged children and adolescents. Bull. WHO 2007, 85, 660. [CrossRef]

25. Kuczmarski, R.J.; Ogden, C.L.; Guo, S.S. 2000 CDC growth charts for the United States: Methods and development. Vital Health Stat. 2002, 11, 1-190.

26. Cole, T.J.; Bellizzi, M.C.; Flegal, K.M.; Dietz, W.H. Establishing a standard definition for child overweight and obesity worldwide: International survey. Br. Med. J. 2000, 320, 1240-1243. [CrossRef]

27. Ashwell, M.; Gunn, P.; Gibson, S. Waist-to-height ratio is a better screening tool than waist circumference and BMI for adult cardiometabolic risk factors: Systematic review and meta-analysis. Obes. Rev. 2012, 13, 275-286. [CrossRef]

28. Ekoru, K.; Murphy, G.A.V.; Young, E.H.; Delisle, H.; Jerome, C.S.; Assah, F.; Longo-Mbenza, B.; Nzambi, J.P.D.; On'Kin, J.B.K.; Buntix, F. Deriving an optimal threshold of waist circumference for detecting cardiometabolic risk in sub-Saharan Africa. Int. J. Obes. 2018, 42, 487-494. [CrossRef]

29. Prioreschi, A.; Munthali, R.J.; Kagura, J.; Said, M.R.; De Lucia, R.E.; Micklesfield, L.K. The associations between adult body composition and abdominal adiposity outcomes, and relative weight gain and linear growth from birth to age 22 in the Birth to Twenty Plus cohort, South Africa. PLoS ONE 2018, 13, e0190483. [CrossRef]

30. Lear, S.A.; Toma, M.; Birmingham, C.L.; Frohlich, J.J. Modification of the relationship between simple anthropometric indices and risk factors by ethnic background. Metabolism 2003, 52, 1295-1301. [CrossRef]

31. Otitoola, O.; Oldewage-Theron, W.; Egal, A. Prevalence of overweight and obesity among selected schoolchildren and adolescents in Cofimvaba, South Africa. South Afr. J. Clin. Nutr. 2020, 33, 1-6. [CrossRef]

32. Sekokotla, M.A.; Goswami, N.; Sewani-Rusike, C.R.; Iputo, J.E.; Nkeh-Chungag, B.N. Prevalence of metabolic syndrome in adolescents living in Mthatha, South Africa. Ther. Clin. Risk Manag. 2017, 13, 131-137. [CrossRef]

33. Matjuda, E.N.; Engwa, G.A.; Letswalo, P.B.; Mungamba, M.M.; Sewani-Rusike, C.R.; Nkeh-Chungag, B.N. Association of Hypertension and Obesity with Risk Factors of Cardiovascular Diseases in Children Aged 6-9 Years Old in the Eastern Cape Province of South Africa. Children 2020, 7, 25. [CrossRef]

34. Letswalo, B.P.; Schmid-Zalaudek, K.; Brix, B.; Matjuda, E.N.; Klosz, F.; Obernhumer, N.; Engwa, A.G.; Gaisl, M.; Sewani-Rusike, C.; Fredriksen, P.M.; et al. Cardiometabolic risk factors and early indicators of vascular dysfunction: A cross-sectional cohort study in South African adolescents. BMJ Open 2021, 11, e042955. [CrossRef] [PubMed]

35. Stewart, A.; Marfell-Jones, M.; Olds, T.; Ridder, H. International Standards for Anthropometric Assessment; ISAK: Lower Hutt, New Zealand, 2011. 
36. Centers for Disease Control and Prevention. A SAS Program for the 2000 CDC Growth Charts (ages 0 to $<20$ years); Division of Nutrition, Physical Activity, and Obesity, National Center for Chronic Disease Prevention and Health Promotion, Centers for Disease Control and Prevention: Atlanta, GA, USA, 2014.

37. Kumar, R.; Indrayan, A. Receiver Operating Characteristic (ROC) Curve for Medical Researchers. Indian Pediatr. 2011, 48, 277-287. [CrossRef] [PubMed]

38. Negash, S.; Agyemang, C.; Matsha, T.E.; Peer, N.; Erasmus, R.T.; Kengne, A.P. Differential prevalence and associations of overweight and obesity by gender and population group among school learners in South Africa: A cross-sectional study. BMC Obes. 2017, 4, 29.

39. Umer, A.; Kelley, G.A.; Cottrell, L.E.; Giacobbi, P., Jr.; Innes, K.E.; Lilly, C.L. Childhood obesity and adult cardiovascular disease risk factors: A systematic review with meta-analysis. BMC Public Health 2017, 17, 683.

40. Yoo, E.-G. Waist-to-height ratio as a screening tool for obesity and cardiometabolic risk. Korean J Pediatr. 2016, 59, 425-431. [CrossRef]

41. Adom, T.; Kengne, A.P.; De Villiers, A.; Boatin, R.; Puoane, T. Diagnostic Accuracy of Body Mass Index in Defining Childhood Obesity: Analysis of Cross-Sectional Data from Ghanaian Children. Int. J. Environ. Res. Public Health 2020, 17, 36. [CrossRef]

42. Browning, L.M.; Hsieh, S.D.; Ashwell, M. A systematic review of waist-to-height ratio as a screening tool for the prediction of cardiovascular disease and diabetes: 0.5 could be a suitable global boundary value. Nutr. Res. Rev. 2010, 23, 247-269. [CrossRef]

43. Dong, J.; Wang, S.; Chu, X.; Zhao, J.; Liang, Y.Z.; Yang, Y.B.; Yan, Y.X. Optimal Cut-off Point of Waist to Height Ratio in Beijing and Its Association with Clusters of Metabolic Risk Factors. Curr. Med. Sci. 2019, 39, 330-336. [CrossRef]

44. Peng, Y.; Li, W.; Wang, Y.; Bo, J.; Chen, H. The Cut-Off Point and Boundary Values of Waist-to-Height Ratio as an Indicator for Cardiovascular Risk Factors in Chinese Adults from the PURE Study. PLoS ONE 2015, 10, e0144539. [CrossRef]

45. Matsha, T.E.; Kengne, A.-P.; Yako, Y.Y.; Hon, G.M.; Hassan, M.S.; Erasmus, R.T. Optimal Waist-to-Height Ratio Values for Cardiometabolic Risk Screening in an Ethnically Diverse Sample of South African Urban and Rural School Boys and Girls. PLoS ONE 2013, 8, e71133. [CrossRef]

46. Li, H.; Ji, C.Y.; Zong, X.N.; Zhang, Y.Q. Body mass index growth curves for Chinese children and adolescents aged 0 to 18 years. Chin. J. Pediatr. 2009, 47, 493-498.

47. Freedman, D.S.; Wang, J.; Maynard, L.M.; Thornton, J.C.; Mei, Z.; Pierson, R.N.; Dietz, W.H.; Horlick, M. Relation of BMI to fat and fat-free mass among children and adolescents. Int. J. Obes. 2005, 29, 1-8. [CrossRef]

48. Chung, S. Growth and Puberty in Obese Children and Implications of Body Composition. J. Obes. Metab. Syndr. 2017, 26, 243-250. [CrossRef] [PubMed]

49. Bleil, M.E.; Booth-LaForce, C.; Benner, A.D. Race Disparities in Pubertal Timing: Implications for Cardiovascular Disease Risk Among African American Women. Popul. Res. Policy Rev. 2017, 36, 717-738. [CrossRef]

50. Nicolau, A.L.; de Moraes, O.G.M. Waist Circumference: A Simple Measure for Childhood Obesity? Arq. Bras. Cardiol. 2020, $114,538-539$.

51. Hirschler, V.; Aranda, C.; Calcagno, M.D.L.; Maccalini, G.; Jadzinsky, M. Can Waist Circumference Identify Children with the Metabolic Syndrome? Arch. Pediatr. Adolesc. Med. 2005, 159, 740-744. [CrossRef] [PubMed]

52. Taheri, M.; Kajbaf, T.Z.; Taheri, M.-R.; Aminzadeh, M. Neck Circumference as a Useful Marker for Screening Overweight and Obesity in Children and Adolescents. Oman Med. J. 2016, 31, 170-175. [CrossRef]

53. Mazıcıŏlu, M.M.; Hatipoğlu, N.; Oztürk, A.; Ciçek, B.; Ustünbaş, H.B.; Kurtoğlu, S. Waist circumference and mid-upper arm circumference in evaluation of obesity in children aged between 6 and 17 years. J. Clin. Res. Pediatr. Endocrinol. 2010, 2, $144-150$. [CrossRef]

54. Chaput, J.-P.; Katzmarzyk, P.T.; Barnes, J.D.; Fogelholm, M.; Hu, G.; Kuriyan, R.; Kurpad, A.; Lambert, E.V.; Maher, C.; Maia, J.; et al. Mid-upper arm circumference as a screening tool for identifying children with obesity: A 12-country study. Pediatr. Obes. 2017, 12, 439-445. [CrossRef] [PubMed]

55. Asif, M.; Aslam, M.; Altaf, S. Mid-upper-arm circumference as a screening measure for identifying children with elevated body mass index: A study for Pakistan. Korean J. Pediatr. 2018, 61, 6-11. [CrossRef] [PubMed]

56. McLaren, S.; Steenkamp, L.; McCarthy, H.D.; Rutishauser-Perera, A. Screening for overweight using mid-upper arm circumference (MUAC) among children younger than two years in the Eastern Cape, South Africa. South Afr. J. Clin. Nutr. 2020, 33, 1-4. [CrossRef] 